\title{
Low-dose leptin reverses skeletal muscle, autonomic, and neuroendocrine adaptations to maintenance of reduced weight
}

Michael Rosenbaum, Rochelle Goldsmith, Daniel Bloomfield, Anthony Magnano, Louis Weimer, Steven Heymsfield, Dympna Gallagher, Laurel Mayer, Ellen Murphy, and Rudolph L. Leibel

Columbia University College of Physicians and Surgeons, New York, New York, USA.

\begin{abstract}
Maintenance of a reduced body weight is accompanied by decreased energy expenditure that is due largely to increased skeletal muscle work efficiency. In addition, decreased sympathetic nervous system tone and circulating concentrations of leptin, thyroxine, and triiodothyronine act coordinately to favor weight regain. These "weight-reduced" phenotypes are similar to those of leptin-deficient humans and rodents. We examined metabolic, autonomic, and neuroendocrine phenotypes in 10 inpatient subjects ( 5 males, 5 females [ 3 never-obese, 7 obese]) under 3 sets of experimental conditions: (a) maintaining usual weight by ingesting a liquid formula diet; (b) maintaining a $10 \%$ reduced weight by ingesting a liquid formula diet; and (c) receiving twice-daily subcutaneous doses of leptin sufficient to restore 8 am circulating leptin concentrations to pre-weight-loss levels and remaining on the same liquid formula diet required to maintain a $10 \%$ reduced weight. During leptin administration, energy expenditure, skeletal muscle work efficiency, sympathetic nervous system tone, and circulating concentrations of thyroxine and triiodothyronine returned to pre-weight-loss levels. These responses suggest that the weight-reduced state may be regarded as a condition of relative leptin insufficiency. Prevention of weight regain might be achievable by strategies relevant to reversing this leptin-insufficient state.
\end{abstract}

\section{Introduction}

In rodents, imposed weight-loss decreases energy expenditure per unit of metabolic mass, reflecting metabolic opposition to loss of body fat (1). Maintenance of a $10 \%$ or greater reduction in body weight by either obese or never-obese humans is also accompanied by a reduction in energy expenditure beyond that predicted by loss of body mass (2-5). In such subjects, sympathetic nervous system (SNS) tone and circulating concentrations of leptin and bioactive thyroid hormones are reduced, while parasympathetic nervous system (PNS) tone is increased (2-9). These changes are of comparable magnitude in obese and lean individuals (2) and may be causally related to the reduction in energy expenditure that occurs following weight loss. This decrease in energy expenditure is of sufficient magnitude to account - in part - for the very high recidivism to obesity in otherwise successfully weight-reduced subjects

The major "effector organ" for this decline in energy expenditure is skeletal muscle (3). Maintenance of a $10 \%$ reduction in body weight is associated with a $20-30 \%$ decline in energy expended in physical activity regardless of whether calculated from physical activity logs (10-12), assessed by bicycle ergometry and indirect calorimetry (3), or measured by NMR spectroscopy as the ATP cost per muscle contraction during low-level physical activity (3, 12). The decrease in energy expenditure is not due to reduced time spent in physical activity $(2,3,10)$.

Nonstandard abbreviations used: NREE, nonresting energy expenditure; PNS, parasympathetic nervous system; REE, resting energy expenditure; RQ, respiratory quotient; SNS, sympathetic nervous system; T3, triiodothyronine; T4, thyroxine; TEE, 24-hour energy expenditure; TEF, thermic effect of feeding; TRH, thyrotropin-releasing hormone; TSH, thyroid-stimulating hormone.

Conflict of interest: The authors have declared that no conflict of interest exists.

Citation for this article: J. Clin. Invest. 115:3579-3586 (2005).

doi:10.1172/JCI25977.
The metabolic phenotypes of weight-reduced humans, leptindeficient humans, and leptin-deficient rodents are similar but not identical (13-15). Murine leptin deficiency is characterized by hyperphagia, hypometabolism, decreased $\mathrm{T}$ cell-mediated immunity, decreased SNS activity, stunted skeletal growth, decreased hypothalamic-pituitary-thyroid and -gonadal axis activities, and increased circulating concentrations of corticosterone $(13,14,16,17)$. Congenitally leptin-deficient children have a similar phenotype, except that energy expenditure, statural growth, and circulating concentrations of cortisol are all within normal limits (15). Administration of leptin to leptindeficient rodents in doses that restore circulating leptin concentrations to their physiological range increases energy expenditure, decreases energy intake, increases SNS output $(18,19)$, and normalizes hypothalamic-pituitary-adrenal, thyroid, and gonadal function (20-23). Leptin administration to leptin-deficient humans decreases energy intake and increases activity of the hypothalamic-pituitary-thyroid axis $(15,24)$. Yet in humans and rodents that are not leptin deficient, induction of weight loss requires doses of leptin that produce 10 -fold elevations of plasma leptin concentrations $(23,25)$.

We have previously reported that restoration of circulating concentrations of leptin in weight-reduced individuals to levels that were present prior to weight reduction reverses the decline in circulating concentrations of bioactive thyroid hormones and in energy expenditure that characterize the weight-reduced state (4). Similarly, Welt et al. (26) reported that leptin administration (0.08 $\mathrm{mg} / \mathrm{kg} / \mathrm{d}$ ) to women with secondary hypothalamic amenorrhea due to reduced fat mass reversed the decline in hypothalamic-pituitary-gonadal axis function and raised circulating concentrations of triiodothyronine (T3) and thyroxine (T4); no such effects were detected when leptin was administered in similar doses to eumenorrheic women without reduced fat mass. 


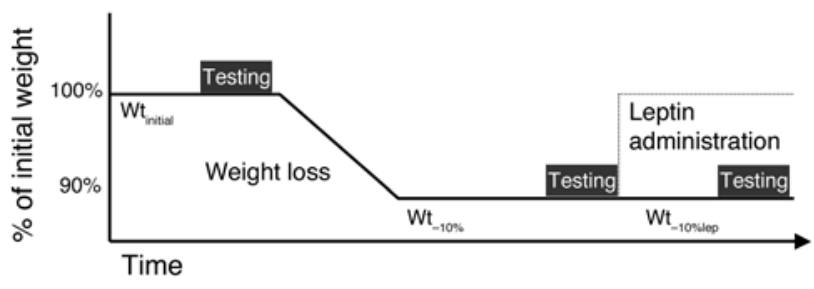

Figure 1

Schematic of protocol.

In the present study, we tested the hypothesis that administration of leptin to weight-reduced subjects in doses that would restore circulating leptin concentrations to levels present prior to weight loss would reverse the changes in skeletal muscle metabolism and autonomic function that accompany maintenance of a reduced body weight (2-9).

\section{Results}

Protocol and leptin dosing. This protocol was designed to examine the effects of leptin administration on the weight-reduced phenotype of subjects maintaining a $10 \%$ reduced body weight (Figure 1 ). Subjects were inpatients at the General Clinical Research Center and on a liquid formula diet throughout the study. Briefly, subjects were admitted at their usual body weight (designated as "Wt $\mathrm{t}_{\text {initial }}$ "), and caloric intake was titrated until weight was stable, at which time subjects underwent the measurements of metabolic, autonomic, and neuroendocrine function described in Methods. Achievement of weight stability and testing required an average of 8 weeks (range 6-10 weeks). Subjects were then placed on $800 \mathrm{kcal} / \mathrm{d}$ of the same liquid formula diet until they had lost $10 \%$ of their usual weight. Subjects required an average of 8 weeks to lose $10 \%$ of initial weight (range 5-10 weeks). Following weight loss, daily caloric ingestion of the liquid formula diet was adjusted until weight was stable (designated as "Wt-10\%"), and the same testing performed at $\mathrm{W} \mathrm{t}_{\text {initial }}$ was repeated. Subjects required an average of 7 weeks to complete studies at $\mathrm{Wt}_{-10 \%}$ (range 6-8 weeks). Following completion of studies at $\mathrm{Wt}_{-10 \%}$, and while remaining on the same daily caloric intake, subjects received 5 weeks of twice-daily leptin injections in doses calculated to maintain circulating leptin concentrations at levels present prior to weight loss (designated as " $\mathrm{Wt}_{-10 \% \text { lep }}$ ") and within dosing ranges that have been reported to have little if any effect on the parameters measured in this study in subjects at usual weight $(25,26)$. Leptin doses were titrated until trough concentrations, measured just prior to leptin administration at $8 \mathrm{am}$, were comparable to those levels present prior to weight loss. When subjects who had lost $10 \%\left(\mathrm{Wt}_{-10 \%}\right)$ of their initial body weight $\left(\mathrm{W} t_{\text {initial }}\right)$ received subcutaneous leptin (Wt-10\%lep), plasma leptin concentrations at $8 \mathrm{am}$ were significantly higher than those values observed at $\mathrm{Wt}_{-10 \%}$ and not significantly different from those observed at $\mathrm{Wt}_{\text {initial }}$ (Figure 2). In studies of leptin administration to a cohort of 16 obese and lean males and females at usual weight who were assessed monthly for 6 months while receiving leptin, Heymsfield et al. (25) reported no significant effects of r-metHuLeptin administration in doses of 0.01-0.10 $\mathrm{mg} / \mathrm{kg} / \mathrm{d}$ on body weight or composition. Welt et al. (26) reported no significant effects of administration of 0.08 $\mathrm{mg} / \mathrm{kg} / \mathrm{d}$ r-metHuLeptin (over a 1-month period) on body composition, am cortisol levels, or thyroid hormones in 8 women with hypothalamic amenorrhea. In the present study, mean \pm SEM total daily leptin doses relative to body mass at $\mathrm{Wt}_{-10 \%}$ were $0.068 \pm 0.01$ $\mathrm{mg} / \mathrm{kg}$ (range $0.019-0.121 \mathrm{mg} / \mathrm{kg} / \mathrm{d}$ ) divided q12 hours (8 am and $8 \mathrm{pm})$, i.e., within ranges that have been previously shown to have no significant effect on body composition or hypothalamic-pituitary-thyroid function in obese or lean subjects at usual weight. It should be noted that twice-daily administration of exogenous leptin does not mimic the normal pulsatility of leptin secretion (27-30) and that the effects on leptin pulsatility of maintenance of a reduced body weight or of exogenous leptin administration in humans on leptin pulsatility, to our knowledge, have not been reported. Therefore, the decline in 8 am circulating leptin concentrations at $\mathrm{Wt}_{-10 \%}$ and restoration of 8 am circulating concentrations of leptin to those present prior to weight loss during leptin administration at $\mathrm{Wt}_{-10 \% \text { lep }}$ do not necessarily reflect total daily amounts of circulating leptin or the pulsatility of leptin secretion during the different study periods. No significant effects of gender or initial somatotype were noted on any results, except that lean subjects consistently required less time (mean 6 weeks) to lose $10 \%$ of their weight than obese subjects (mean 9 weeks).

Body composition. Administration of leptin to subjects ingesting the same number of calories required to maintain their weight at $\mathrm{Wt}_{-10 \%}$ resulted in further reduction in body weight. Loss of fat mass accounted for $67.2 \% \pm 8.5 \%$ of the weight lost during leptin administration, similar to $71 \% \pm 6.7 \%$ of weight lost as fat observed during weight loss on an $800-\mathrm{kcal} / \mathrm{d}$ diet from $\mathrm{Wt}_{\text {initial }}$ to $\mathrm{Wt}_{-10 \%}$ (Figure 3 ).

Energy expenditure. At all study periods, the respiratory quotient (RQ) at rest was not significantly different from the diet formula quotient (by bomb calorimetry) of 0.85 . At $\mathrm{Wt}_{-10 \%}$, 24-hour energy expenditure (TEE) and nonresting energy expenditure (NREE; energy expended in physical activity above resting) were decreased out of proportion to changes in body composition from $\mathrm{Wt}_{\text {initial }}$. The relationships among TEE, NREE, and body composition were restored at $\mathrm{Wt}_{\text {-10\%lep }}$ to levels present at $\mathrm{Wt}_{\text {initial }}$ (Figure 4). No significant effects of weight loss or leptin administration on resting energy expenditure (REE) or the thermic effect of feeding (TEF) beyond those predicted by changes in body composition were noted.

Skeletal muscle. At $\mathrm{Wt}_{-10 \%}$, skeletal muscle work efficiency was increased and RQ was decreased at low levels of work (pedaling a bicycle ergometer to generate $10 \mathrm{~W}$ of power) compared with sub-
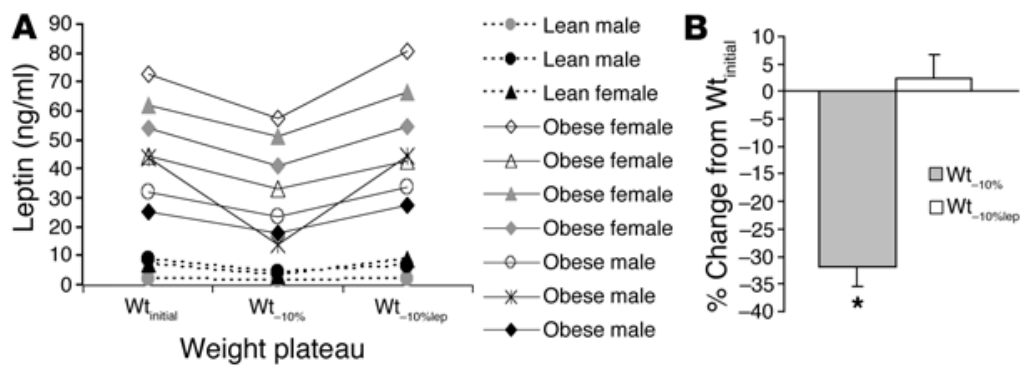

\section{Figure 2}

Effects of weight loss and leptin administration on circulating leptin concentrations. (A) 8 am plasma leptin concentrations at $\mathrm{Wt}_{\text {initial }}, \mathrm{Wt}_{-10 \%}$, and $\mathrm{Wt}_{-10 \% \text { lep. }}$. Circulating leptin concentrations were significantly lower at $\mathrm{Wt}_{-10 \%}$, than at $\mathrm{Wt}_{\text {initial }}$ or at $\mathrm{Wt}_{-10 \% \text { lep. }}$. (B) Percent changes (mean $\pm \mathrm{SEM}$ ) from $\mathrm{Wt}_{\text {tinitial }}$ values in plasma leptin concentrations at $\mathrm{Wt}_{-10 \%}$ and $\mathrm{Wt}_{-10 \% \text { lep. }}{ }^{*} P<0.05$ compared with 0 . 


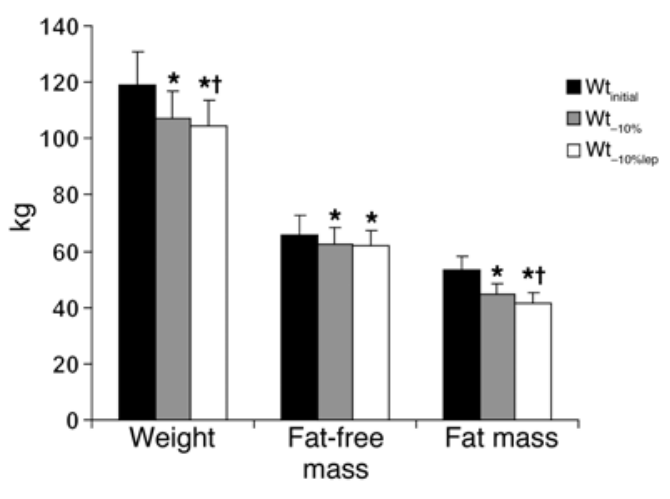

jects at $\mathrm{Wt}_{\text {initial, }}$, similar to our previous observations (3). At $\mathrm{Wt}_{-10 \%}$, the gross mechanical efficiency (GME) of skeletal muscle while bicycling to generate $10 \mathrm{~W}$ of power was approximately $23 \%$ higher than at $\mathrm{Wt}_{\text {initial }}$ and was fully reversed during leptin administration

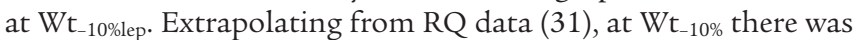
an approximate $12 \%$ decrease - compared with $\mathrm{Wt}_{\text {initial }}$ - in the percentage of calories derived from the oxidation of glucose during bicycling to generate $10 \mathrm{~W}$ of power. This decrease in the use of glucose as fuel following weight loss was only evident at low levels of work (bicycling to generate $10 \mathrm{~W}$ but not $25 \mathrm{~W}$ or more of power) (Figure 4). The effect was fully reversed at $\mathrm{Wt}_{-10 \% \text { lep }}$ (Figure 4).

Thyroid. At $\mathrm{Wt}_{-10 \%}$, circulating concentrations of $\mathrm{T} 3$ and $\mathrm{T} 4$ were reduced compared with $\mathrm{Wt}_{\text {initial }}$. At $\mathrm{Wt}_{-10 \% \text { lep }}$, circulating $\mathrm{T} 4$ and $\mathrm{T} 3$ concentrations were, respectively, similar to and higher than those at $\mathrm{Wt}_{\text {initial }}$. At $\mathrm{Wt}_{-10 \%}$ and $\mathrm{Wt}_{-10 \% \text { lep }}$, circulating thyroid-stimulating hormone (TSH) concentrations were significantly reduced compared with $\mathrm{Wt}_{\text {initial }}$ values; no significant effects of leptin administration on circulating TSH concentrations were noted (Figure 5).

Autonomic function. Maintenance of a $10 \%$ reduced body weight was associated with decreased SNS activity (measured by heart rate analysis and by urinary catecholamine excretion) and increased PNS activity (measured by heart rate analysis). Administration of leptin to weight-reduced subjects reversed the decline in SNS activity and 24-hour urinary epinephrine excretion but did not significantly alter the decline in 24-hour urinary norepinephrine excretion or the increase in PNS activity (Figure 6). There was no significant effect of weight loss or leptin administration on the intrinsic heart rate.

\section{Figure 3}

Subject characteristics. Administration of exogenous leptin to weightreduced subjects ingesting an isocaloric diet was associated with a significant decline in body weight and fat mass but not fat-free mass. Data refer to 10 subjects: 5 males, 5 females; 7 obese, 3 neverobese. Mean \pm SEM values at each weight plateau are presented in Supplemental Table 1 (supplemental material available online with this article; doi:10.1172/JCI25977DS1). ${ }^{*} P<0.05$ versus $W t_{\text {initial; }}$; ${ }^{+} P<0.05$ versus $\mathrm{Wt}_{-10 \%}$.

\section{Discussion}

In human beings, maintenance of reduced body weight is met by coordinate metabolic, neuroendocrine, and autonomic responses that favor the regain of lost weight (2-9). We have previously reported that the administration of exogenous leptin to weightreduced subjects in doses that restore circulating leptin concentrations to those present prior to weight loss reverses the declines in energy expenditure and circulating concentrations of bioactive thyroid hormones that accompany the maintenance of a reduced body weight (4). Other studies $(25,26)$ have demonstrated that administration of similar doses of exogenous leptin to subjects at usual weight has no significant effect on body composition or thyroid function. The major findings of the present study are that administration of leptin to weight-reduced individuals also reverses the changes in skeletal muscle energetics and SNS activity that would otherwise act coordinately to promote weight regain $(32,33)$. These in vivo responses of weight-reduced humans to leptin are concordant with in vitro and in vivo studies of leptin effects on skeletal muscle, autonomic nervous system activity, and neuroendocrine axes and demonstrate that leptin administration to weight-reduced subjects reverses many of the metabolic phenotypes that characterize the weight-reduced state.

Maintenance of a reduced body weight is associated with a significant decrease in TEE of approximately 300-500 kcal/d greater than that predicted by changes in body mass and composition (2, $3)$. This decrease in TEE is due predominantly to reduced energy expended in physical activity (NREE), reflecting increased work efficiency of skeletal muscle (3). We find that both the decline in

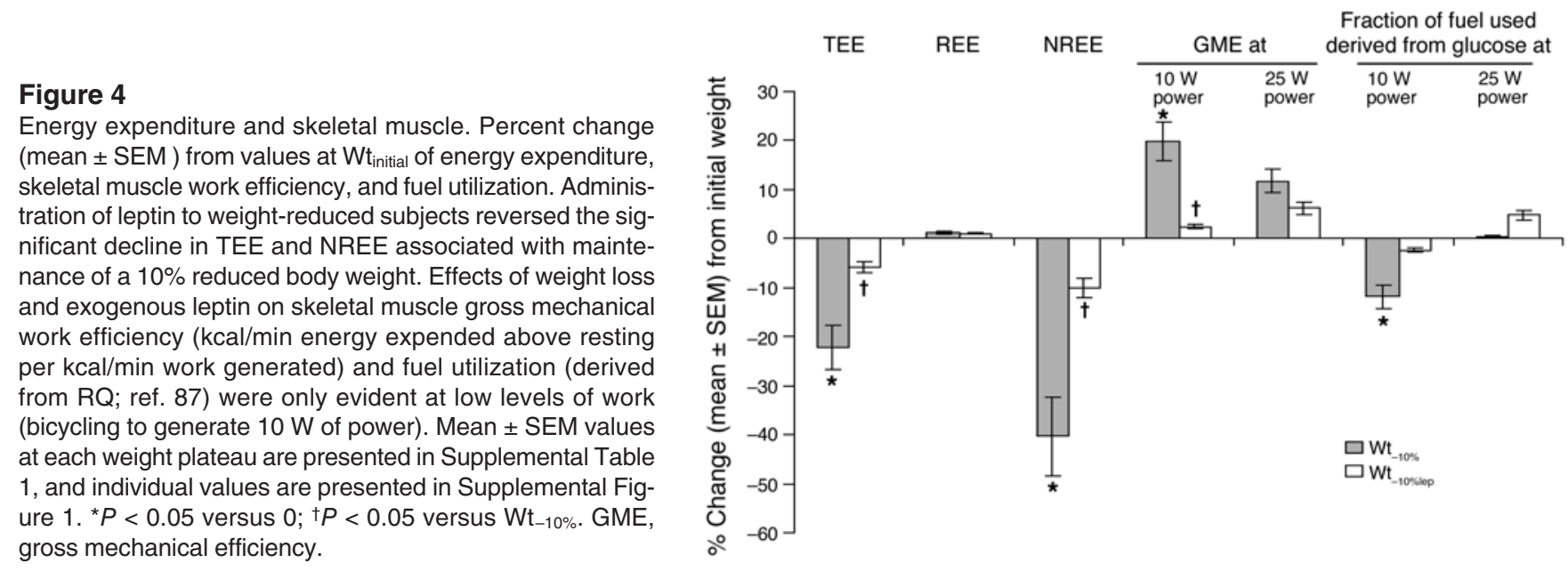




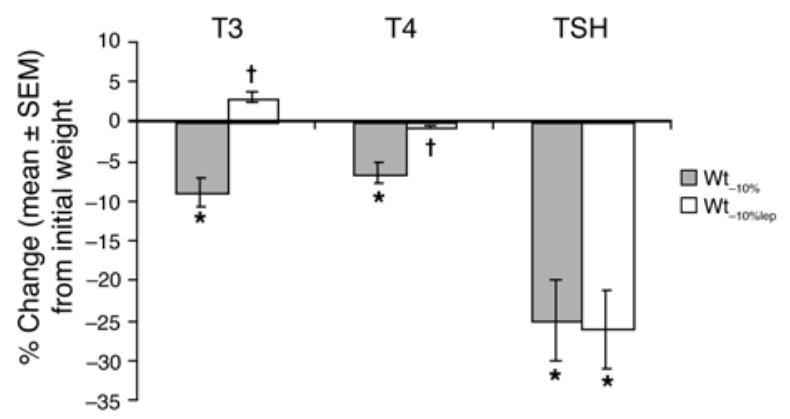

energy expenditure and increased work efficiency of muscle are reversed by leptin administration to weight-reduced subjects. Leptin could affect skeletal muscle function via direct interaction with muscle cells and/or by engaging hypothalamic/brain stem pathways regulating autonomic and neuroendocrine function. Skeletal muscle expresses the short and long isoforms of the leptin receptor (34), and incubation of skeletal muscle from lean mice with leptin stimulates oxygen consumption (35). Both systemic and intracerebroventricular leptin administration increase insulin-mediated glucose uptake in rat skeletal muscle (36-38), and leptin increases both glucose and fatty acid oxidation in rodent skeletal muscle in vitro $(34,36,39-42)$. Declines in circulating concentrations of bioactive thyroid hormones have been shown to promote increased expression of the more chemomechanically efficient isoforms of the myosin heavy chain (MHC) that preferentially use free fatty acids as fuel $(43,44)$. Resultant shifts in MHC isoform expression may contribute to the leptin-reversible increase in skeletal muscle work efficiency and utilization of fatty acids noted following weight loss in this study.

SNS tone appears to be crucial to leptin-mediated increases in energy expenditure in rats, since neonatal chemical sympathectomy severely attenuates the increased energy expenditure, loss of fat mass, and increased insulin-mediated glucose uptake that occur following intracereberoventricular leptin administration to rats (45). Leptin deficiency is associated with decreased SNS tone as measured by blood pressure changes during a cold pressor test in humans (46) and a leptin-reversible decline in brown adipose tissue thermogenesis in mice (47). We examined the effects of leptin administration to weight-reduced subjects on SNS and PNS inputs to the heart (heart rate analyses during pharmacological blockade) and on 24-hour secretion of norepinephrine (predominantly from SNS nerve endings) and epinephrine (predominantly from the adrenal gland). These organ-specific measures of autonomic activity do not necessarily reflect systemic

\section{Figure 6}

Autonomic function. Percent change (mean \pm SEM) from values at $\mathrm{Wt}_{\mathrm{initial}}$ of autonomic nervous system tone. Administration of leptin to weight-reduced subjects reversed the significant declines in one 24-hour urinary epinephrine excretion and SNS tone (measured by heart rate analysis during serial pharmacological blockade), which are associated with maintenance of a $10 \%$ reduced body weight. No effect of leptin was noted on urinary dopamine excretion, on the significant decline in urinary norepinpehrine excretion, or on the significant increase in parasympathetic tone associated with maintenance of a $10 \%$ reduced body weight. Mean \pm SEM values at each weight plateau are presented in Supplemental Table 1. ${ }^{\star} P<0.05$ versus 0 ; ${ }^{\dagger} P<0.05$ versus $\mathrm{Wt}_{-10 \%}$.

\section{Figure 5}

Neuroendocrine function. Percent change (mean \pm SEM) from values at $\mathrm{Wt}_{\mathrm{initial}}$ of T3, T4, and TSH. Administration of leptin to weight-reduced subjects reversed the significant declines in circulating concentrations of T4 and T3, but not TSH, that are associated with the maintenance of a $10 \%$ reduced body weight. Mean \pm SEM values at each weight plateau are presented in Supplemental Table 1. ${ }^{*} P<0.05$ versus 0 ; ${ }^{\dagger} P<0.05$ versus $\mathrm{Wt}_{-10 \%}$.

autonomic nervous system tone. We found that leptin reverses the decline in SNS activity (measured by heart rate analysis and urinary epinephrine but not norepinpehrine excretion) but does not significantly affect the increase in PNS activity associated with weight loss that has been previously reported $(6,48,49)$. These data suggest that that changes in SNS, but not PNS, activity following weight loss are due to decreased circulating leptin concentrations. Leptin-mediated SNS effects probably reflect both the peripheral stimulatory effects of leptin on adrenal epinephrine release and centrally mediated increases in sympathetic outflow. These inferences are supported by direct effects of leptin on epinephrine release from porcine adrenal medullary cells (50) and the increases in circulating concentrations of epinephrine and norepinephrine, renal sympathetic nerve activity, heart rate, arterial pressure, and sympathoexcitation of brown adipose tissue (51-54) following systemic leptin infusion, or injection of leptin into the dorsomedial hypothalamus in rats. To our knowledge, no other studies have examined the effects of leptin administration on PNS tone in states of leptin insufficiency.

The reversal by leptin of the weight loss-associated decline in activity of the hypothalamic-pituitary-thyroid axis activity associated with maintenance of a reduced body weight is consistent with the known leptin-induced increased hypothalamic expression of proopiomelanocortin and its cleavage product $\alpha-\mathrm{MSH}$, as well as leptin's inhibitory effects on hypothalamic expression of agouti-related peptide (AgRP). The decline in hypothalamic $\alpha-\mathrm{MSH}$ and increase in AgRP act coordinately to decrease pro-thyrotropin-releasing hormone (pro-TRH) release. In addition, leptin directly stimulates pro-TRH gene expression in the paraventricular nucleus of the hypothalamus $(55,56)$. The decline in $\alpha-\mathrm{MSH}$ and increase in AgRP act coordinately to decrease pro-TRH release in the hypothalamus $(57,58)$. In addition, leptin directly stimulates pro-TRH gene expression in the paraventricular nucleus of the hypothalamus $(21,59,60)$.

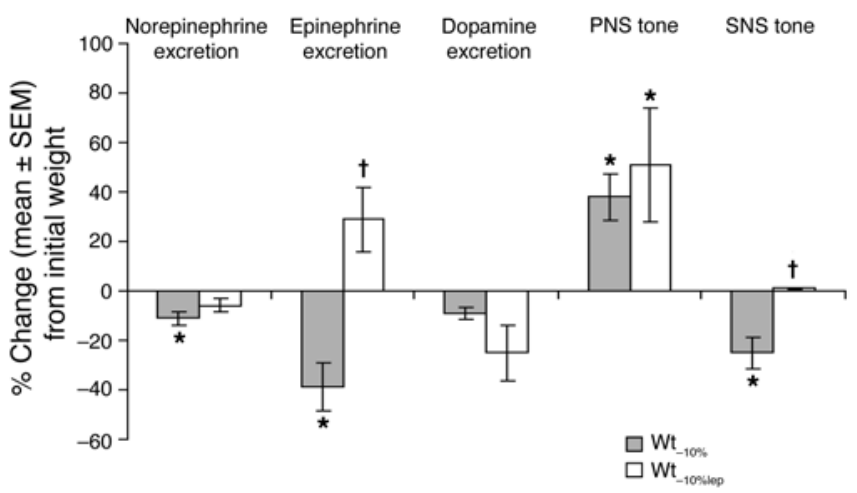


Leptin-stimulated TRH release alone would not account for our observation that 5 weeks of leptin administration to weightreduced subjects raised circulating concentrations of T3 and T4 but not TSH, nor the observation of Farooqi et al. (15) that 1-6 months of leptin administration to humans with congenital leptin deficiency raised circulating concentrations of bioactive thyroid hormones but not TSH. The potent effect of leptin on circulating concentrations of bioactive thyroid hormones - without effects on circulating levels of TSH - suggests that leptin directly stimulates $\mathrm{T} 4$ release from the thyroid gland and/or increases the bioactivity of TSH. In rats, the thyroid gland expresses the long isoform of the leptin receptor, and administration of leptin to euthyroid, leptin-sufficient animals increases circulating concentrations of T3 and T4, thyroid gland weight, and volume of the thyroid follicle epithelium without affecting circulating concentrations of TSH $(61,62)$. Increased TRH secretion increases TSH bioactivity in vitro and in vitro by apparent effects on sialation of TSH (63), and TSH bioactivity is decreased in low-TRH states (analogous to the lowTRH state of weight-reduced humans) (64-67).

Leptin administration in doses that raise circulating concentrations of leptin to levels within the physiological range for nonobese individuals reverses the hyperphagia and decreased circulating concentrations of gonadotropins that characterize congenital leptin deficiency $(14,24,68,69)$. Similar doses of leptin decrease hunger and increase satiety in individuals who are hypoleptinemic by virtue of lipodystrophy (70). We find that 5 weeks of leptin administration in doses similar to those that are effective in individuals who cannot synthesize leptin (24) reverses many metabolic/neuroendocrine aspects of the weight-reduced phenotype. Why should leptin have such striking physiological effects in weight-reduced subjects when, in individuals at usual body weight, doses that elevate circulating concentrations of the hormone nearly 10 -fold have little effect? The primary functional role of leptin is apparently to defend - not reduce - body fat by increasing food seeking and decreasing energy expenditure when fat stores are insufficient $(20,32,71)$. The threshold for determination of leptin sufficiency in this context is determined by anatomic and functional characteristics of the hypothalamus and other parts of the brain that are, in turn, determined by genetic and developmental factors. Recent indications of the structural plasticity of the hypothalamus, and of the role of leptin in mediating some of that plasticity, suggest that the threshold for leptin action may be influenced by developmental process and chronic changes in somatic fat stores $(72,73)$. Physiological responses to concentrations of leptin below and above this threshold are very asymmetrical: decreased concentrations of leptin trigger full- strength counterregulation to what is "perceived" as a threat to survival; concentrations of leptin above the threshold - signaling "sufficient" or excess fat stores - are not responded to vigorously, or at all (74). This asymmetry permits the deposition of additional fat stores in environmental circumstances when this is possible, conveying survival advantage in most instances. Variations in this threshold determine the minimum amounts of body fat defended by individuals. Hence the comparable responses to reductions in body fat in both lean and obese individuals (2). In this model, the experiments described here are examples of restoration of circulating leptin concentrations to points above each subject's threshold with resultant reversal of leptin-insufficient/weight-reduced phenotypes. An alternative hypothesis is that the reversal of weightreduced metabolic phenotypes in subjects receiving leptin might be secondary to temporal resolution of "carry-over" effects of the metabolic changes occurring during weight loss (2), rather than to effects of leptin per se. This hypothesis is not supported by the observation that reduction in TEE persists in subjects who have sustained weight loss for extended periods of time (6-24 months) in circumstances of enforced caloric restriction in the Biosphere 2 project (75), lifestyle modification (76), or bariatric surgery (77).

Studies of longer duration are needed to determine whether chronic reactivation of the leptin axis following weight loss might assist in the long-term maintenance of a reduced body weight. Physiologically, the induction of weight loss and the maintenance of reduced body weight are very different $(2,78)$. Pharmacologic and other strategies designed to maintain lost body weight may, for these reasons, be more effective than those designed to induce weight loss (74).

\section{Methods}

Subjects. Ten subjects ( 5 male, 5 female [ 3 never-obese, 7 obese]); mean \pm SEM age $32.2 \pm 2.9$ years) were admitted to the General Clinical Research Center at Columbia University Medical Center and remained as in-patients throughout the study (Table 1). All subjects had been stable at their maximal lifetime weights for at least 6 months prior to admission, were in good health, and were taking no medications. Subjects with BMI (weight $[\mathrm{kg}] /[\text { height }(\mathrm{m})]^{2}$ ) greater than $30 \mathrm{~kg} / \mathrm{m}^{2}$ were classified as "obese" while subjects with BMI less than $30 \mathrm{~kg} / \mathrm{m}^{2}$ were classified as "never-obese" (79). Studies were approved by the Institutional Review Board of The New York Presbyterian Medical Center and are consistent with guiding principles for research involving humans (80). Written informed consent was obtained from all subjects.

Protocol. The protocol is schematized in Figure 1. Subjects were inpatients at the Clinical Research Center at Columbia University Medical Center throughout this study. As described previously (81), subjects were

\section{Table 1}

Subject characteristics

\begin{tabular}{|c|c|c|c|c|c|c|c|c|c|}
\hline \multirow[b]{2}{*}{$\begin{array}{l}\text { Subject } \\
\text { characteristics }\end{array}$} & \multicolumn{3}{|c|}{$W t_{\text {initial }}$} & \multicolumn{3}{|c|}{$\mathrm{Wt}_{-10 \%}$} & \multicolumn{3}{|c|}{$\mathrm{Wt}_{-10 \% \text { lep }}$} \\
\hline & $\begin{array}{l}\text { Lean } \\
(n=3)\end{array}$ & $\begin{array}{l}\text { Obese } \\
(n=7)\end{array}$ & $\begin{array}{c}\text { All } \\
(n=10)\end{array}$ & $\begin{array}{l}\text { Lean } \\
(n=3)\end{array}$ & $\begin{array}{l}\text { Obese } \\
(n=7)\end{array}$ & $\begin{array}{c}\text { All } \\
(n=10)\end{array}$ & $\begin{array}{l}\text { Lean } \\
(n=3)\end{array}$ & $\begin{array}{l}\text { Obese } \\
(n=7)\end{array}$ & $\begin{array}{c}\text { All } \\
(n=10)\end{array}$ \\
\hline Weight (kg) & $69.0 \pm 8.0$ & $140.5 \pm 11.4$ & $119.0 \pm 13.5$ & $63.0 \pm 7.2$ & $125.9 \pm 11.6^{A}$ & $107.3 \pm 5.8^{A}$ & $60.5 \pm 6.9$ & $122.8 \pm 10.3^{A}$ & $104.3 \pm 11.2^{\mathrm{A}, \mathrm{B}}$ \\
\hline BMI $\left(\mathrm{kg} / \mathrm{m}^{2}\right)$ & $24.7 \pm 2.6$ & $47.4 \pm 3.4$ & $40.6 \pm 4.4$ & $22.6 \pm 2.4$ & $42.1 \pm 3.8^{\mathrm{A}}$ & $36.3 \pm 4.0^{\mathrm{A}}$ & $21.7 \pm 1.8$ & $41.4 \pm 3.6^{A}$ & $35.3 \pm 3.8^{A, B}$ \\
\hline Fat-free mass (kg) & $52.0 \pm 6.4$ & $71.6 \pm 6.1$ & $65.9 \pm 5.5$ & $50.1 \pm 6.0$ & $67.9 \pm 5.6^{A}$ & $62.6 \pm 4.9^{A}$ & $50.4 \pm 6.0$ & $66.6 \pm 6.0^{\mathrm{A}}$ & $61.7 \pm 5.1^{\mathrm{A}}$ \\
\hline Fat mass $(\mathrm{kg})$ & $16.9 \pm 0.5$ & $68.8 \pm 7.3$ & $53.1 \pm 9.9$ & $12.8 \pm 1.4$ & $58.1 \pm 6.5^{\mathrm{A}}$ & $44.7 \pm 8.3^{A}$ & $10.0 \pm 0.6$ & $55.4 \pm 6.5^{A}$ & $41.6 \pm 8.2^{\mathrm{A}, \mathrm{B}}$ \\
\hline Leptin (ng/ml) & $6.3 \pm 1.9$ & $47.9 \pm 6.2$ & $35.5 \pm 7.8$ & $4.1 \pm 2.9$ & $34.1 \pm 5.5^{A}$ & $25.0 \pm 6.4^{A}$ & $6.1 \pm 2.0$ & $51.9 \pm 7.0^{\mathrm{B}}$ & $38.2 \pm 8.3^{B}$ \\
\hline
\end{tabular}

${ }^{A} P<0.05$ versus $\mathrm{Wt}_{\text {initial; }}{ }^{\mathrm{B} P}<0.05$ versus $\mathrm{Wt}_{-10 \%}$. 
fed a liquid formula diet (40\% of calories as fat [corn oil], $45 \%$ as carbohydrate [glucose polymer], and $15 \%$ as protein [casein hydrolysate]) plus vitamin and mineral supplements, in quantities sufficient to maintain a stable weight (defined as an average daily weight variation of less than 10 $\mathrm{g} / \mathrm{d}$ for at least 2 weeks). This weight plateau is designated as $\mathrm{W} \mathrm{t}_{\text {initial. }}$. To prevent changes in physical fitness as a result of the 6-7 months in-patient stay, and to insure that subjects did not substantially vary their in-patient physical activity levels during the study, either of which might affect skeletal muscle metabolism/performance, each subject's aerobic fitness was measured by bicycle ergometry upon admission and was then maintained at that level throughout the study. Aerobic fitness was defined as the anaerobic threshold, the point at which pulmonary ventilation increases out of linear proportion to $\mathrm{O}_{2}$ consumption due to the buffering of lactate by endogenous bicarbonate. Supervised exercise (treadmill walking or stationary bicycling) was performed 3 times per week at specified intensities and durations that were adjusted to maintain each subject's anaerobic threshold at their initial level throughout the study.

Following completion of studies (described below) at $\mathrm{Wt}_{\text {initial }}$, subjects were provided $800 \mathrm{kcal} / \mathrm{d}$ of the same liquid formula diet until they had lost $10 \%$ of $\mathrm{Wt}_{\text {initial }}$. Once $10 \%$ weight loss had been achieved, caloric intake was adjusted upward until subjects were again weight stable as described above. This weight plateau is designated as $\mathrm{Wt}_{-} 10 \%$.

Following completion of studies at $\mathrm{Wt}_{-10 \%}$, subjects received 5 weeks of bid ( 8 am and $8 \mathrm{pm}$ ) s.c. injections of recombinant human leptin (A-100; provided by Amgen Inc.) in doses that were calculated to achieve circulating concentrations of leptin at 8 am (preinjection) equal to those measured at $\mathrm{Wt}_{\text {initial }}(4,25)$. Initial total daily leptin doses were: $0.08 \mathrm{mg} / \mathrm{kg}$ fat mass at $\mathrm{Wt}_{-10 \%} /$ dose in males and $0.14 \mathrm{mg} / \mathrm{kg}$ fat mass at $\mathrm{Wt}_{-10 \%} /$ dose in females (4). Circulating leptin concentrations at 8 am were measured weekly in subjects receiving leptin, and dosages were adjusted until circulating leptin concentrations were similar to those measured at $8 \mathrm{am}$ at $\mathrm{Wt}_{\text {initial. }}$. This weight plateau is designated as $\mathrm{Wt}_{-10 \% \text { lep }}$.

At the end of each of the 3 weight plateaus, the following measurements were made starting at 9-10 am with subjects in a postabsorptive state:

Body composition. Body composition by dual energy $\mathrm{x}$-ray absorptiometry (DXA) (7).

Energy expenditure. TEE was measured by empirical determination of weight-maintenance caloric intake (2). The constancy of body composition, as well as weight stability, was confirmed by demonstrating that the $\mathrm{RQ}\left(V_{\mathrm{CO}} / \mathrm{VO}_{2}\right)$ for subjects at rest in the postabsorptive state was not significantly different from the liquid formula diet formula quotient (FQ) of 0.85 (see Results) (2). Since weight and body composition are constant, the energy ingested as liquid formula must match the total daily energy expenditure. We have previously shown that TEE measured by such caloric titration is highly correlated with TEE directly measured by the doubly-labeled water method $\left(r^{2}=0.88\right)(81)$. Since at $\mathrm{Wt}_{-10 \% \text { lep }}$ each subject remained on a diet that was isocaloric to that at $\mathrm{Wt}_{-10 \%}$, any change in $\mathrm{TEE}$ as a result of leptin administration must be reflected by change in stored energy. At $\mathrm{Wt}_{-10 \% \text { lep }}$, TEE was calculated as: calories fed plus or minus any change in whole body energy content between $\mathrm{Wt}_{-10 \%}$ and $\mathrm{Wt}_{-10 \% \text { lep }}$, divided by the number of days over which leptin was administered. The energy content of intercurrent weight change was calculated using DXA measurements of body composition obtained at the end of the $\mathrm{Wt}_{-10 \% \text { lep }}$ weight plateau compared with that obtained at the end of the $\mathrm{Wt}_{-10 \%}$ weight plateau. Chemical energy content was assigned as $9.4 \mathrm{kcal} / \mathrm{g}$ wet weight of fat mass and 0.91 $\mathrm{kcal} / \mathrm{g}$ wet weight of fat-free mass excluding bone (82). REE was measured by indirect (hood) calorimetry. TEF was calculated as calories expended above REE following ingestion of liquid formula calories equivalent to $60 \%$ of REE measured from 8 to 9 am on the day of testing, as previously described (81). Daily energy expenditure above REE and TEF was desig- nated as NREE (energy expended above resting in physical activity). NREE was calculated as NREE $=$ TEE $-($ REE + TEF $)$. To correct for the non-zero intercept of regressions relating energy expenditure to body composition (83), residual values of REE, TEE, and NREE were calculated for subjects at $\mathrm{Wt}_{-10 \%}$ and $\mathrm{Wt}_{-10 \% \text { lep }}$ as the difference between measured energy expenditures and values predicted from the regression equations relating energy expenditure to fat mass and fat-free mass at $\mathrm{Wt}_{\text {initial }}$ (83). Data regarding the effects of weight loss and leptin administration on energy expenditure in 4 subjects ( 3 never-obese, 1 obese; 2 males, 2 females) have been reported previously (4).

Skeletal muscle. Skeletal muscle work efficiency was measured by indirect calorimetry during graded bicycle ergometry (3). Following a 10-minute period of accommodation, subjects pedaled at $60 \mathrm{rpm}$ to generate $10 \mathrm{~W}$ of power for 4 minutes. Resistance was then increased so that power output was $25 \mathrm{~W}$ for 4 minutes. Oxygen uptake $\left(\mathrm{VO}_{2}\right)$, carbon dioxide production $\left(V \mathrm{VO}_{2}\right)$, and the RQ $\left(V \mathrm{VO}_{2} / V \mathrm{O}_{2}\right)$ were measured continuously using a SensorMedics Vmax 29 metabolic cart attached to the subject via a mouthpiece (3). Skeletal muscle work efficiency was expressed as gross mechanical efficiency (GME): the ratio of power generated in $\mathrm{kcal} /$ min to change in energy expenditure above REE in $\mathrm{kcal} / \mathrm{min}$ at power outputs of $10 \mathrm{~W}$ and $25 \mathrm{~W}$ (3). The metabolic fuel mix being oxidized was determined from RQ values (3).

Autonomic nervous system activity. In 9/10 subjects, PNS and SNS activity while resting supine were measured by analysis of changes in mean ECG R-R interval during sequential pharmacological blockade with the muscarinic PNS blocker atropine, followed by the cardioselective SNS blocker esmolol. The mean R-R interval from two 5-minute pre-blockade samples was used as the baseline against which the mean R-R intervals of the post-atropine measurement and post-atropine plus esmolol measurement were compared. Parasympathetic activity was calculated as the mean R-R interval change after atropine compared with baseline. Sympathetic activity was calculated as mean R-R interval change after atropine plus esmolol compared with the atropine alone. Intrinsic heart rate was defined as heart rate following complete SNS and PNS blockade (6). SNS activity measured by pharmacological blockade reflects the action of catecholamines (predominantly norepinephrine) released at nerve endings and from the adrenal gland (predominantly epinephrine), as well as the sensitivity, number, and relative proportion of cardiac $\alpha$ - and $\beta$-adrenoreceptors (84). In order to examine the effects of weight loss and leptin administration on catecholamine production, 24-hour urine catecholamine excretion (dopamine, epinephrine, norepinephrine) was assayed by HPLC (85) at each study period in all subjects. The intraassay coefficients of variation for these assays are less than $5 \%$. The interassay coefficients of variation for assays of dopamine, epinephrine, and norepinephrine are, respectively, $6.2 \%, 5.7 \%$, and $7.1 \%$.

Neuroendocrine. 8 am circulating plasma concentrations of leptin were measured by ELISA (Diagnostic Systems Laboratories Inc.), and serum concentrations of thyroid stimulating hormone (TSH), T4, and T3 by RIA (86). The intra- and interassay coefficients of variation for each of these assays are less than 5\%. Data regarding the effects of weight loss and leptin administration on thyroid hormones in 4 subjects ( 3 never-obese, 1 obese; 2 males, 2 females) have been reported previously (4).

All women were in the follicular phase of their menstrual cycle at the start of testing. The order of testing was similar, but not identical, in all subjects. In larger study groups, we have not found a significant effect of the order of testing or of duration of time spent at reduced weight on any of these parameters (2).

Statistics. Data were analyzed using the STATISTICA 6.0 software package (StatSoft Inc.). Data are presented as mean \pm SEM. Intragroup comparisons (same subjects at different study periods) were made by ANOVA with 
repeated measures. Between-group comparisons (males versus females, obese versus never-obese) were made by ANOVA. Statistical significance was prospectively defined as $\mathrm{P} \alpha<0.05$.

\section{Acknowledgments}

We gratefully acknowledge the invaluable assistance of all our volunteers and of the nursing staff and nutrition staff of the Irving Center for Clinical Research at The New York Presbyterian Hospital, Columbia University College of Physicians \& Surgeons. These studies were supported by NIH grants DK64773, RR00645, and
P30-DK26687. Leptin A-100 was generously provided by Alex De Paoli, Amgen Inc., Thousand Oaks, California, USA.

Received for publication June 16, 2005, and accepted in revised form October 3, 2005.

Address correspondence to: Michael Rosenbaum, Russ Berrie Medical Science Pavilion, Columbia University Medical College, Room 620, 1150 St. Nicholas Avenue, New York, New York 10032, USA. Phone: (212) 305-9949; Fax: (212) 8 51-5306; E-mail: mr475@columbia.edu.
1. Keesey, R.E. 1980. A set-point analysis of the regulation of body weight. In Obesity. A.J. Stunkard, editor. W.B. Saunders. Philadelphia, Pennsylvania, USA. $144-165$.

2. Leibel, R., Rosenbaum, M., and Hirsch, J. 1995. Changes in energy expenditure resulting from altered body weight. N. Eng. J. Med. 332:621-628.

3. Rosenbaum, M., et al. 2003. Effects of weight change on skeletal muscle work efficiency in human subjects. Am. J. Physiol. 285:R183-R192.

4. Rosenbaum, M., Murphy, E., Heymsfield, S., Matthews, D., and Leibel, R. 2002. Low dose leptin administration reverses effects of sustained weightreduction on energy expenditure and circulating concentrations of thyroid hormones. J. Clin. Endocrinol. Metab. 87:2391-2394.

5. Doucet, E., et al. 2003. Greater than predicted decrease in energy expenditure during exercise after body weight loss in obese men. Clin. Sci. 105:85-95.

6. Aronne, L., Mackintosh, R., Rosenbaum, M., Leibel, R., and Hirsch, J. 1995. Autonomic nervous system activity in weight gain and weight loss. Am. J. Physiol. 38:R222-R225.

7. Rosenbaum, M., Hirsch, J., Murphy, E., and Leibel, R. 2000. The effects of changes in body weight on carbohydrate metabolism, catecholamine excretion, and thyroid function. Am. J. Clin. Nutr. 71:1421-1432.

8. Emdin, M., et al. 2001. Hyperinsulinemia and autonomic nervous system dysfunction in obesity: effects of weight loss. Circulation. 103:513-519.

9. Rissanen, P., Franssila-Kallunki, A., and Rissanen, A. 2001. Cardiac parasympathetic activity is increased by weight loss in healthy obese women. Obes. Res. 9:637-643.

10. Weinsier, R., et al. 2000. Energy expenditure and free-living physical activity in black and white women: comparison and after weight loss. Am. J. Clin. Nutr. 71:1138-1146.

11. Rosenbaum, M., and Leibel, R. 2001. Reply to R. Weinsier et al. Am. J. Clin. Nutr. 73:657-658.

12. Newcomer, B., Larson-Meyer, D., Hunter, G., and Weinsier, R. 2001. Skeletal muscle metabolism in overweight and post-overweight women: an isometric exercise study using (31)P magnetic resonance spectroscopy. Int. J. Obes. 25:1309-1315.

13. Trayhurn, P., Thurlby, P., and James, W. 1977. Thermogenic defect in pre ob/ob mice. Nature. 266:60-62.

14. Breslow, M., et al. 1999. Effect of leptin deficiency on metabolic rate in ob/ob mice. Am. J. Physiol. 276:E443-E449

15. Farooqi, I., et al. 2002. Beneficial effects of leptin on obesity, T cell hyporesponsiveness, and neuroendocrine/metabolic dysfunction of human congenital leptin deficiency. J. Clin. Invest. 110:1093-1103. doi:10.1172/JCI200215693.

16. Montez, J., et al. 2005. Acute leptin deficiency, leptin resistance, and the physiological response to leptin withdrawal. Proc. Natl. Acad. Sci. U. S. A 102:2537-2542.

17. Maclean, P., et al. 2004. Enhanced metabolic efficiency contributes to weight regain after weight loss in obesity-prone rats. Am. J. Physiol. 287:R1306-R1315.

18. Tang-Christensen, M., Havel, P., Jacobs, R., Larsen, P., and Cameron, J. 1999. Central administration of leptin inhibits food intake and activates the sympathetic nervous system in rhesus macaques. J. Clin. Endocrinol. Metab. 84:711-717.

19. Satoh, N., et al. 1999. Sympathetic activation of leptin via the ventromedial hypothalamus: leptininduced increase in catecholamine secretion. Diabetes. 48:1787-1793.

20. Ahima, R., et al. 1996. Role of leptin in the neuroendocrine response to fasting. Nature. 382:250-252.

21. Harris, M., et al. 2001. Transcriptional regulation of the thyrotropin-releasing hormone gene by leptin and melanocortin signaling. J. Clin. Invest. 107:111-120.

22. Legradi, G., Emerson, C., Ahima, R., Flier, J., and Lechan, R. 1998. Leptin prevents fasting-induced suppression of prothyrotropin-releasing hormone messenger ribonucleic acid in neurons of the hypothalamic paraventricular nucleus. Endocrinology. 138:2569-2576.

23. Campfield, L., Smith, F., Guisez, Y., Devos, R., and Burn, P. 1995. Recombinant mouse OB protein: evidence for a peripheral signal linking adiposity and central neural networks. Science. 269:546-548.

24. Farooqi, I., et al. 1999. Effects of recombinant leptin therapy in a child with congenital leptin deficiency. N. Eng. J. Med. 341:879-884.

25. Heymsfield, S.B., et al. 1999. Recombinant leptin for weight loss in obese and lean adults: a randomized, controlled, dose-escalation trial. JAMA. 292:1568-1575.

26. Welt, C., et al. 2004. Recombinant human leptin in women with hypothalamic amenorrhea. N. Eng. J. Med. 351:987-997.

27. Yildiz, B., Suchard, M., Wong, M., McCann, S., and Licinio, J. 2004. Alterations in the dynamics of circulating ghrelin, adiponectin, and leptin in human obesity. Proc. Natl. Acad. Sci. U. S. A. 101:10434-10439.

28. Saad, M., et al. 1998. Diurnal and ultradian rhythmicity of plasma leptin: effects of gender and adiposity. J. Clin. Endocrinol. Metab. 83:453-459.

29. Licinio, J., et al. 1997. Human leptin levels are pulsatile and inversely related to pituitary-adrenal function. Nat. Med. 3:575-579.

30. Licinio, J., et al. 1998. Sex differences in circulating human leptin pulse amplitude: clinical implications. J. Clin. Endocrinol. Metab. 83:4140-4147.

31. McArdle, W., Katch, F., and Katch, V. 1996. Exercise physiology. Williams \& Wilkins. Baltimore, Maryland, USA.145-147.

32. Leibel, R., Chua, S., and Rosenbaum, M. 2001 Chapter 157: obesity. In The metabolic and molecular bases of inherited disease. C. Scriver, A. Beaudet, W. Sly, and D. Valle, editors. McGraw-Hill. New York, New York, USA. 3965-4028.

33. Ahima, R., Kelly, J., Elmquist, J., and Flier, J. 1999. Distinct physiologic and neuronal responses to decreased leptin and mild hyperleptinemia. Endocrinology. 140:4923-4931.

34. Solinas, G., et al. 2004. The direct effect of leptin on skeletal muscle thermogenesis is mediated by substrate cycling between de novo lipogenesis and lipid oxidation. FEBS Lett. 577:539-544.

35. Dulloo, A., et al. 2002. Leptin directly stimulates thermogenesis in skeletal muscle. FEBS Lett. 515:109-113.

36. Yaspelkis, B., et al. 2004. Chronic leptin treatment enhances insulin-stimulated glucose disposal in skeletal muscle of high-fat fed rodents. Life Sci. 74:1801-1816.

37. Haque, M., et al. 1999. Role of the sympathetic nervous system and insulin in enhancing glucose uptake in peripheral tissues after intrahypothalamic injection of leptin in rats. Diabetes. 48:1706-1712.

38. Ceddia, R., WIlliam, W., and Curi, R. 1999. Comparing effects of leptin and insulin on glucose metabolism in skeletal muscle: evidence for an effect of leptin on glucose uptake and decarboxylation. Int. J. Obes. 23:75-82.

39. Kamohara, S., Burcelin, R., Halaas, J., Friedman, J., and Charron, M. 1997. Acute stimulation of glucose metabolism in mice by leptin treatment. Nature. 389:374-377.

40. Berti, L., and Gammeltoft, S. 1999. Leptin stimulates glucose uptake in $\mathrm{C} 2 \mathrm{C} 12$ muscle cells by activation of ERK2. Mol. Endocrinol. 157:121-130.

41. Muoio, D., Dohm, G., Fiedorek, F., Tapscott, E., and Coleman, R. 1997. Leptin directly alters lipid partitioning in skeletal muscle. Diabetes. 46:1360-1363.

42. Minokoshi, Y., et al. 2002. Leptin stimulates fattyacid oxidation by activating AMP-activated protein kinase. Nature. 415:339-343.

43. Reggiani, C., et al. 1997. Chemo-mechanical energy transduction in relation to myosin isoform composition in skeletal muscle fibres of the rat. J. Physiol. 15:449-460.

44. Caiozzo, V., Baker, M., and Baldwin, K. 1998. Novel transitions in MHC isoforms: separate and combined effects of thyroid hormone and mechanical unloading. J. Appl. Physiol. 85:2237-2248.

45. Dobbins, R., Szczepaniak, L., Zhang, W., and McGarry, J. 2003. Chemical sympathectomy alters regulation of body weight during prolonged ICV leptin infusion. Am. J. Physiol. 284:E778-E787.

46. Ozata, M., Ozdemir, I., and Licinio, J. 1999. Human leptin deficiency caused by a missense mutation: multiple endocrine defects, decreased sympathetic tone, and immune system dysfunction indicate new targets for leptin action, greater central than peripheral resistance to the effects of leptin, and spontaneous correction of leptin-mediated defects. J. Clin. Endocrinol. Metab. 84:3686-3695.

47. Scarpace, P., Matheny, M., Pollock, B., and Tumer, N. 1997. Leptin increase uncoupling protein expression and energy expenditure. Am. J. Physiol. 274:E226-E230.

48. Trombetta, I., et al. 2003. Weight loss improves neurovascular and muscle metaboreflex control in obesity. Am. J. Physiol. 285:H974-H982.

49. Grassi, G., et al. 1998. Body weight reduction, sympathetic nerve traffic, and arterial baroreflex in obese normotensive humans. Circulation. 97:2037-2042.

50. Takekoshi, K., et al. 2001. Leptin stimulates catecholamine synthesis in a PKC-dependent manner 
in cultured porcine adren medullary chromaffin cells. Endocrinology. 142:4961-4971.

51. Satoh, N., et al. 1999. Sympathetic activation of leptin via the ventromedial hypothalamus: leptininduced increase in catecholamine secretion. Diabetes. 48:1787-1793.

52. Rahmouni, K., Haynes, W., Morgan, D., and Mark, A. 2003. Role of melanocortin-4 receptors in mediating renal sympathoactivation to leptin and insulin. J. Neurosci. 23:5998-6004.

53. Marsh, A., et al. 2003. Cardiovascular responses evoked by leptin acting on neurons in the ventromedial and dorsomedial hypothalamus. Hypertension. 42:488-493.

54. Haynes, W., Morgan, D., Walsh, S., Mark, A., and Sivitz, W. 1997. Receptor-mediated regional sympathetic nerve activation by leptin. J. Clin. Invest. 100:270-278

55. Benoit, S., Clegg, D., Seeley, R., and Woods, S. 2004. Insulin and leptin as adiposity signals. Recent Prog. Horm. Res. 59:267-285.

56. van Dijk, G., et al. 1999. Metabolic, gastrointestinal, and CNS neuropeptide effects of brain leptin administration in the rat. Am. J. Physiol. Endocrinol. Metab. 276:R1425-R1433.

57. Wardlaw, S. 2001. Clinical review 127: obesity as a neuroendocrine disease: lessons to be learned from proopiomelanocortin and melanocortin receptor mutations in mice and men. J. Clin. Endocrinol. Metab. 86:1442-1446

58. Kim, M., et al. 2000. The central melanocortin system affects the hypothalamo-pituitary thyroid axis and may mediate the effect of leptin. J. Clin. Invest. 105:1005-1011.

59. Nillni, E., et al. 2000. Leptin regulates prothyrotropin-releasing hormone biosynthesis. Evidence for direct and indirect pathways. J. Biol. Chem. 275:36124-36133.

60. Guo, F., Bakal, K., Minokoshi, Y., and Hollenberg, A. 2004. Leptin signaling targets the thyrotropinreleasing hormone gene promoter in vivo. Endocrinology. 145:2221-2227.

61. Teixeira, C., Ramos, C., Marco, T., Passos, M., and Moura, E. 2003. Leptin injection during lactation alters thyroid function in adult rats. Horm. Metab. Res. 35:367-372.
62. Nowak, K., et al. 2002. Rat thyroid gland expresses the long form of leptin receptors, and leptin stimulates the function of the gland in euthyroid nonfasted animals. Int. J. Mol. Med. 9:31-34.

63. Menezes-Ferreira, M., Petrick, P., and Weintraub, B. 1986. Regulation of thyrotropin (TSH) bioactivity by TSH-releasing hormone and thyroid hormone. Endocrinology. 118:2125-2130.

64. Yamada, M., et al. 1997. Tertiary hypothyroidism and hyperglycemia in mice with targeted disruption of the thyrotropin-releasing hormone gene. Proc. Natl. Acad. Sci. U. S. A. 94:10862-10887.

65. Collu, R., et al. 1997. A novel mechanism for isolated central hypothyroidism: inactivating mutations in the thyrotropin-releasing hormone receptor gene. J. Clin. Endocrinol. Metab. 82:1561-1565.

66. Rabeler, R., et al. 2004. Generation of thyrotropinreleasing hormone receptor 1 -deficient mice as an animal model of central hypothyroidism. Mol. Endocrinol. 18:1450-1460.

67. Hass, V., et al. 2005. Leptin and body weight regulation in patients with anorexia nervosa before and during weight recovery. Am. J. Clin. Nutr. 81:889-896.

68. Farooqi, I., et al. 2000. Dominant and recessive inheritance of morbid obesity associated with melanocortin 4 receptor deficiency. J. Clin. Invest. 106:271-279.

69. Montague, C.T., et al. 1997. Congenital leptin deficiency is associated with severe early-onset obesity in humans. Nature. 387:903-908.

70. McDuffie, J., et al. 2004. Effects of exogenous leptin on satiety and satiation in patients with lipodystrophy and leptin insufficiency. J. Clin. Endocrinol. Metab. 89:4258-4263.

71. Chehab, F. 2000. Leptin as a regulator of adipose tissue mass and reproduction. Trends Pharmacol. Sci. 21:309-314.

72. Bouget, S., Draper, S., and Simerly, R. 2004. Trophic action of leptin on hypothalamic neurons that regulate feeding. Science. 304:108-110.

73. Pinto, S., et al. 2004. Rapid rewiring of arcuate nucleus feeding circuits by leptin. Science. 304:63-64.

74. Leibel, R. 2002. The role of leptin in the control of body weight. Nutr. Rev. 60:S15-S19.

75. Weyer, C., et al. 2000. Energy metabolism after 2 y of energy restriction: the biosphere 2 experiment. Am. J. Clin. Nutr. 72:946-953.

76. Leibel, R., and Hirsch, J. 1984. Diminished energy requirements in reduced-obese patients. Metabolism. 33:164-170.

77. van Gemert, W.G., et al. 2000. Energy, substrate and protein metabolism in morbid obesity before, during and after massive weight loss. Int. J. Obes. 24:711-718.

78. Rosenbaum, M., et al. 1997. Effects of weight change on plasma leptin concentrations and energy expenditure. J. Clin. Endocrinol. Metab. 82:3647-3654.

79. Expert panel on the identification, evaluation, and treatment of overweight in adults. 1998. Clinical guidelines on the identification, evaluation, and treatment of overweight and obesity in adults: executive summary. Am. J. Clin. Nutr. 68:899-917.

80. American Physiological Society. 2002. Guiding principles for research involving animals and human beings. Am. J. Physiol. Regul. Integr. Comp. Physiol. 283:R281-R283.

81. Rosenbaum, M., et al. 1996. A comparative study of different means of assessing long-term energy expenditure in humans. Am. J. Physiol. 270:R496-R504.

82. Pietrobelli, A., et al. 2002. Sexual dimorphism in energy content of weight change. Int. J. Obes. Relat. Metab. Disord. 26:1339-1348.

83. Ravussin, E., Lillioja, S., Anderson, T., Christin, L., and Bogardus, C. 1986. Determinants of 24hour energy expenditure in man. Methods and results using a respiratory chamber. J. Clin. Invest. 78:1568-1578.

84. Hirsch, J., and Mackintosh, R. 2003. Measuring activity of the autonomic nervous system in humans. Obes. Res. 11:2-4.

85. Causon, R., and Carruthers, M. 1982. Measurement of catecholamines in biological fluids by high-performance liquid chromatography: a comparison of fluorimetric with electrochemical detection. J. Chromatogr. 229:301-309.

86. Miles, L. 1977. Chapter 4. In Handbook of radioimmunoassay. G. Abraham, editor. Marcel Dekker. New York, New York, USA. 679-680.

87. McArdle, W., Katch, F., and Katch, V. 1996. Exercise physiology. WIlliams \& Wilkins. Baltimore, Maryland, USA. 101-116. 